\title{
Echocardiographic abnormalities of tricuspid valve motion in pulmonary embolism
}

\author{
TADAAKI IWASAKI, MASAHO TANIMOTO, TADAO YAMAMOTO, SHUZO MAKIHATA, \\ YOSHITAKA KAWAI, SUSUMU YORIFUJI
}

From the First Department of Internal Medicine, Hyogo College of Medicine, Nishinomiya, fapan

SUMMARY Echocardiographic findings in five patients with pulmonary embolism were studied. Tricuspid echocardiograms showed abnormalities in valve motion, that is a monophasic triangular wave during diastole in all the patients as well as an increased dimension of the right ventricle. An "a" dip of the pulmonary valve echocardiogram was also recognised in all five. Later tricuspid echocardiograms regained the normal M-shaped configuration.

The monophasic triangular pattern of the tricuspid valve during diastole may be related to the shorter duration of tricuspid valve opening compared with that of the mitral valve. Tachycardia cannot explain this difference between tricuspid and mitral valve motion, which seems to be caused by a prolonged isovolumic relaxation time of the right ventricle resulting in a delayed opening of the tricuspid valve. These results were obtained by comparing these data with those of control subjects and patients with chronic right ventricular overloading resulting from atrial septal defect.

The most common haemodynamic derangement in patients with acute or subacute pulmonary embolism is pulmonary hypertension in frequent association with right heart failure. It has been suggested that acute depression of contractile force, which a previously normal right ventricle can generate, ensues. Echocardiography is a useful non-invasive method to evaluate cardiac function; we used it to assess right ventricular function sequentially in five patients with pulmonary embolism. There is little information on echocardiographic findings in this disorder,,$^{1-3}$ and our findings have not been previously described. Attempts were made to ascertain the possible mechanisms of the abnormal configuration of tricuspid valve motion during diastole. These data were compared with those of normal subjects and patients with chronic right ventricular overload resulting from atrial septal defect.

\section{Subjects and methods}

The diagnosis of pulmonary embolism was confirmed by pulmonary perfusion scan and/or pulmonary arteriogram in all five patients. One of them had a second attack. The instrument used in this study was 
jects with no heart disease and 24 patients with atrial septal defect were studied. Twelve of the 24 had an uncomplicated atrial septal defect with predominant volume overloading of the right ventricle and 12 had a complicated atrial septal defect with pulmonary hypertension (mean pulmonary artery pressures greater than $30 \mathrm{mmHg}$ ) or combined volume and pressure overloading of the right ventricle. Tracings of control subjects were obtained at a heart rate varied by ergometer exercise performed supine.

\section{STATISTICAL ANALYSIS}

The difference between means was assessed for statistical significance by Student's $t$ test. A p value of less than 0.05 was considered to be significant. Regression analysis and Peasson's correlation coefficient were obtained using standard statistical methods.

\section{Case report}

A 34-year-old man was admitted to Hyogo College of Medicine Hospital on 18 November 1977 because of severe dyspnoea and cyanosis. He had undergone thrombophlebotomy of the right femoral vein five years previously when he had had an episode of acute pulmonary embolism. On the day of admission, blood pressure was $124 / 100 \mathrm{mmHg}$, pulse rate $120 / \mathrm{min}$, and respiration rate $30 / \mathrm{min}$. The lung fields were clear to auscultation and percussion. Arterial blood gas analysis revealed a $\mathrm{PO}_{2}$ of $54 \mathrm{mmHg}$, a $\mathrm{PCO}_{2}$ of $26 \cdot 1$ $\mathrm{mmHg}$, and a pH of 7.466 while he was breathing room air. A chest $x$-ray film showed dilatation of the pulmonary artery stem, clear lung fields, and normal heart size. The electrocardiogram showed $S$ waves in lead I, $Q$ waves in lead III, and inverted T waves in V1-4. Serial enzymes showed a transient rise in serum lactic dehydrogenase up to $640 \mathrm{IU}$ without changes in serum aspartate transaminase, pyruvate transaminase, and creatine kinase. A pulmonary perfusion scan disclosed large perfusion defects in both lower fields. After the start of anticoagulation treatment with heparin and warfarin, his condition improved steadily and symptoms went. Sequential echocardiographic examinations were performed, showing the striking abnormalities in tricuspid valve echocardiogram shown in Fig. 1. Tricuspid valve echocardiogram, taken on the 10th day after the embolism (Fig. 1A) showed a monophasic triangular wave during diastole which has not been described previously. The tricuspid echocardiogram taken 40 days later (Fig. 1B) showed persistence of the monophasic triangular configuration during diastole, but the tricuspid valve showed a slow upward motion during early diastole. Ten months later the tricuspid valve echocardiogram
(Fig. 1C) showed the notched diastolic configuration pattern in which probably $\mathrm{E}$ and $\mathrm{A}$ points occur simultaneously, and the interruption of tricuspid closure commonly called a B-B' step. Eighteen months later, the tricuspid valve echocardiogram (Fig. 1D) showed the $M$-shaped configuration during diastole and lengthening of the AC interval. Fig. IA also illustrates the mitral valve echocardiogram taken immediately after admission, which showed the M-shaped appearance during diastole, and it was noticed that the duration of mitral valve opening was longer than that of tricuspid valve opening.

\section{ECHOCARDIOGRAPHIC FINDINGS IN PULMONARY EMBOLISM}

The echocardiographic findings and right-sided catheterisation data in five patients with pulmonary embolism are summarised in Table 1. The characteristic configuration of the monophasic triangular wave of the tricuspid valve during diastole was observed from 12 hours to 40 days after the attack in all the cases. The dimension of the right ventricle measured from 12 hours to 20 days after the attack increased to more than $30 \mathrm{~mm}$ in all cases. The "a" dip of the pulmonary valve echocardiogram was found in all five cases.

The isovolumic relaxation time of the right ventricle in normal subjects varied within a small range from 20 to $30 \mathrm{~ms}(24 \pm 4 \mathrm{~ms}$, mean $\pm S D)$ at heart rates between 50 and 134 per minute, as shown in Fig. 2. The isovolumic relaxation time was found to correlate with the heart rate $(r=-0.715, p<0.05)$. Thus, the correction for heart rate is required for the isovolumic relaxation time (Table 2). The mean isovolumic relaxation time for the group with uncomplicated atrial septal defect was $30.9 \mathrm{~ms}$ and was slightly prolonged. The isovolumic relaxation time was significantly prolonged in the groups with pulmonary embolism and a complicated atrial septal defect. The To-Tc interval was inversely related to the heart rate $(r=-0.924$, p <0.05) (Fig. 3). This value corrected for heart rate for groups with atrial septal defect and pulmonary embolism was significantly shortened as compared with that for control groups (Table 2). The Q-Tc interval was found not to correlate with the heart rate $(r=-0.06, p>0.05)$ (Fig. 4), and it was not different in groups with pulmonary embolism compared with that for the control group, as shown in Table 2. This indicates that the timing of the tricuspid valve closure for pulmonary embolism was not altered. The Q-P interval was inversely related to the heart rate $(r=-0.959)$ (Fig. 5), and this value for pulmonary embolism was similar to that for the control group (Table 2). This observation shows that the opening of the tricuspid valve was delayed while timing of the pulmonary valve closure was not significantly altered. 


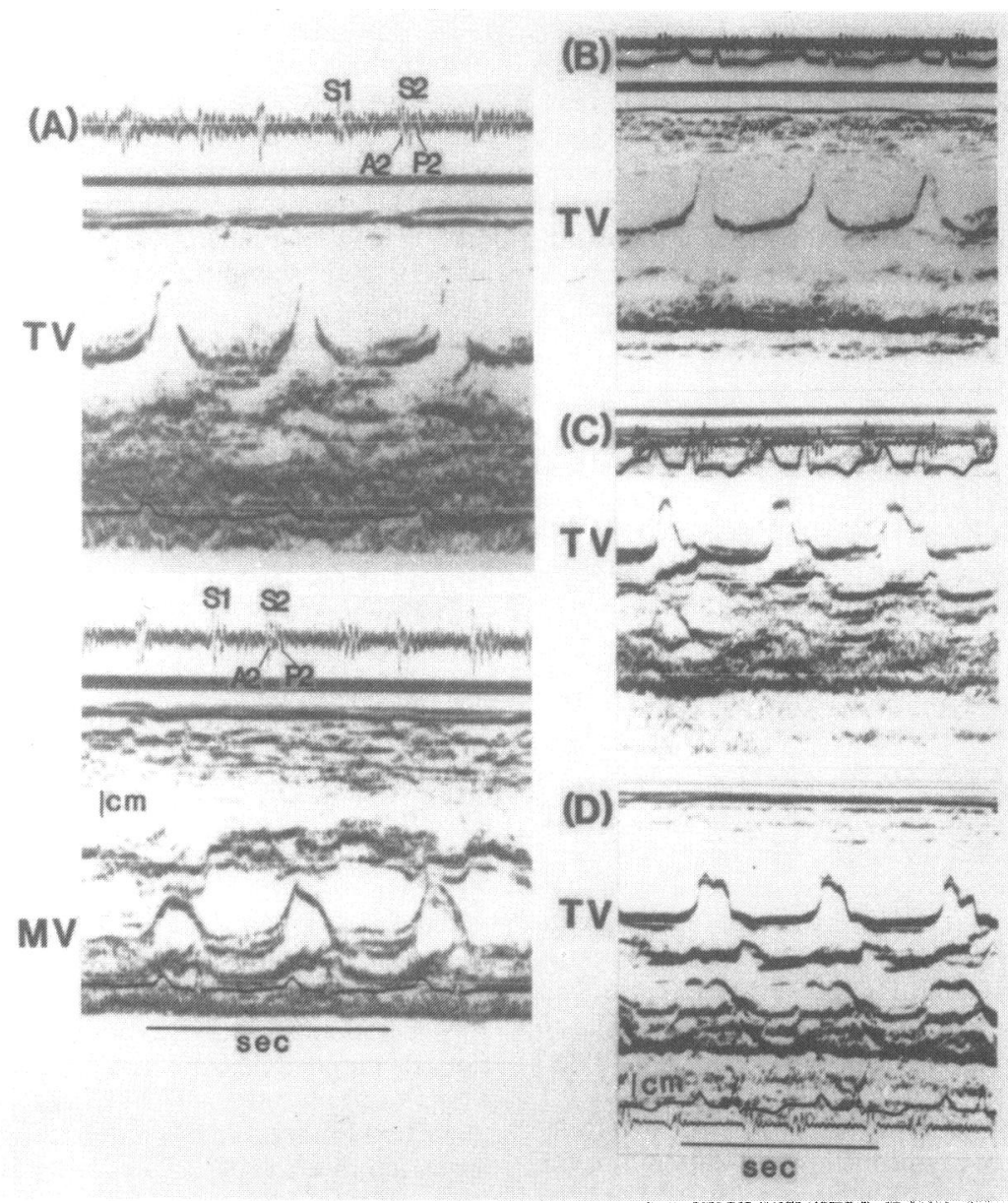

Fig. 1 Tracing from a patient with pulmonary embolism. (A) Recorded 10 days afterwards. The tricuspid valve echocardiogram showed the monophasic triangular wave during the diastolic phase. The mitral valve echocardiogram was recorded at the same time as the tricuspid valve, and the opening period of the mitral valve was longer than that of the tricuspid valve. (B) Recorded 40 days after the attack showed the tricuspid valve moving slowly and anteriorly during early diastolic phase. (C) Recorded 10 months after the attack showed the BB' step. (D) Recorded 18 months after the attack and showed the M-shaped pattern. TV, tricuspid valve; $M V$, mitral valve; $S 1$, first heart sound; $S 2$, second heart sound; $A 2$, second heart sound of aortic valve; $P 2$, second sound of pulmonary valve.

\section{Discussion}

Several echocardiographic studies on pulmonary embolism have described the increased dimension of the right ventricle and paradoxical motion of interventricular septum..$^{1-3}$ To our knowledge, this is the first demonstration of the striking abnormalities of tricuspid valve motion during diastole, that is the monophasic triangular wave produced by a single opening- closing movement instead of the initial early diastolic opening, mid-diastolic closure, and atrial reopening. These abnormal findings were confirmed in all the five patients by repeated echocardiographic examination performed from 12 hours to 40 days after pulmonary embolism.

It was suggested that this peculiar wave is produced by the fusion of $\mathrm{E}$ and $\mathrm{A}$ points as a result of tachycardia which is known to produce the monophasic trian- 
Table 1 Echocardiographic and haemodynamic findings

\begin{tabular}{|c|c|c|c|c|c|c|c|c|c|}
\hline \multirow{3}{*}{$\begin{array}{l}\text { Case } \\
\text { No. }\end{array}$} & \multirow{3}{*}{$\begin{array}{l}\text { Age }(y) \\
\text { and sex }\end{array}$} & \multirow{3}{*}{$\begin{array}{l}\text { Time after } \\
\text { onset }\end{array}$} & \multicolumn{6}{|c|}{ Echocardiographic findings } & \multirow{3}{*}{$\begin{array}{l}\text { Haemodynamics } \\
(\mathrm{mmHg})\end{array}$} \\
\hline & & & \multicolumn{2}{|c|}{ Tricuspid valve echo } & \multirow[b]{2}{*}{$\begin{array}{l}\text { RVDd } \\
(\mathrm{mm})\end{array}$} & \multicolumn{3}{|c|}{ Pulmonary valve echo } & \\
\hline & & & $\begin{array}{l}\text { Monophasic } \\
\text { triangular } \\
\text { wave }\end{array}$ & $\begin{array}{l}\text { M-shaped } \\
\text { pattern }\end{array}$ & & $\begin{array}{l}\text { "a"dip } \\
(\mathrm{mm})\end{array}$ & $\begin{array}{l}b-c \\
(\mathrm{~mm} / \mathrm{s})\end{array}$ & $\begin{array}{l}e-f \\
(\mathrm{~mm} / \mathrm{s})\end{array}$ & \\
\hline 1 & $34 M$ & $\begin{array}{l}10 \mathrm{~d} \\
40 \mathrm{~d} \\
10 \mathrm{mth} \\
18 \mathrm{mth} \\
24 \mathrm{~h}\end{array}$ & $\begin{array}{l}+ \\
+\end{array}$ & + & $\begin{array}{l}38 \\
45 \\
45 \\
45 \\
40\end{array}$ & $\begin{array}{l}3 \\
3 \\
1 \cdot 5 \\
0 \\
7\end{array}$ & $\begin{array}{l}360 \\
380 \\
435 \\
520 \\
214\end{array}$ & $\begin{array}{l}2 \\
4 \cdot 5 \\
9 \\
0 \\
36\end{array}$ & $\begin{array}{l}\text { RV: } 40 / 14 \\
\text { RA:a }=14,(\text { mean }=11)\end{array}$ \\
\hline \multirow[t]{2}{*}{3} & $28 M$ & $\begin{array}{l}40 \mathrm{~d} \\
12 \mathrm{~h}\end{array}$ & + & + & $\begin{array}{l}30 \\
30\end{array}$ & $\begin{array}{l}3 \\
3\end{array}$ & $\begin{array}{l}450 \\
250\end{array}$ & $\begin{array}{l}34 \\
8 \cdot 3\end{array}$ & $\begin{array}{l}\text { PA:60/35(45) } \\
\text { RV:60/8 RA(14) }\end{array}$ \\
\hline & & $19 \mathrm{~d}$ & & + & 25 & 0 & 260 & 0 & $\begin{array}{l}\text { PA:34/18(24) } \\
\text { RV:34/13 RA(13) }\end{array}$ \\
\hline \multirow[t]{2}{*}{4} & $26 M$ & $20 \mathrm{~d}$ & + & & 30 & 2 & 400 & 15 & $\begin{array}{l}\text { PA:63/24(35) } \\
\text { RV:63/7 RA(6) }\end{array}$ \\
\hline & & $40 \mathrm{~d}$ & & + & 18 & 4 & 196 & 12 & $\begin{array}{l}\text { PA:29/8(16) } \\
\text { RV:28/6 RA(5) }\end{array}$ \\
\hline 5 & 49F & $12 \mathrm{~h}$ & + & & 40 & 1 & 280 & 11 & \\
\hline
\end{tabular}

RVDd, right ventricular end-diastolic dimension; RV, right ventricle; RA, right atrium; PA, pulmonary artery; +, present.

gular wave of the mitral valve by shortening diastole. ${ }^{4}$ In fact, one factor that obviously influences the appearance of the atrioventricular valve echo is the heart rate. When the heart rate is faster and diastole shorter, there will be no plateau between early and late diastolic filling, and at times the $\mathrm{E}$ and $\mathrm{A}$ points may even merge with each other. This explanation is unlikely in these cases, since the abnormalities of tricuspid valve motion present a striking contrast to the normal appearance of the mitral valve motion in configuration and diastolic duration recorded simultaneously in the same patient, as shown in Fig. 1 and Table 3. The duration of the tricuspid valve opening is significantly shorter than that of the mitral valve. These observations suggest that these abnormalities cannot be accounted for only by the tachycardia. Attempts to define the mechanism of abnormalities of tricuspid valve motion were performed by analysing its relation to cardiac events. The isovolumic relaxation time of the right ventricle was found to be nearly constant in normal subjects over a broad range of heart rates, and at any given rate the duration of this interval was significantly prolonged in the groups with pulmonary embolism and complicated atrial septal defect. This prolongation in these disorders could be related to an increase in pulmonary artery pressure ${ }^{56}$ or an impairment in contractility of the right ventri$\mathrm{cle}^{7}$ but, though pulmonary hypertension secondary to pulmonary embolism was either similar or less severe than that found in the group with atrial septal defect, the isovolumic relaxation time of the right ventricle was more prolonged in the former group (Tables 1 and 2).

This observation indicates that the timing of tricuspid valve opening is delayed in these situations. Thus, the delayed opening of the tricuspid valve is in part responsible for the abnormal configuration of the tricuspid valve in diastole. In this study the Q-P2 interval was not prolonged in the group with pulmonary embolism, indicating that the timing of pulmonary closure is not delayed. The Q-Tc interval was not altered in the groups with pulmonary embolism, demonstrating normal closure of the tricuspid valve.

The reduced To-Tc interval was observed not only in the group with pulmonary embolism but also in that with atrial septal defect, though the monophasic triangular wave of tricuspid valve motion in diastole was recorded in the former, but not in the latter. The peculiar pattern shown on the echocardiogram seems to be related to the significant differences between the two groups in the prolongation of the isovolumic relaxation time resulting in delayed tricuspid valve opening and shortened duration of tricuspid valve opening, as shown in Table 2. The separation of the patients with pulmonary embolism into two subgroups, that is those with and those without the monophasic triangular wave, presumably depends on the same reasons. The normal $M$-shaped configuration of tricuspid valve motion in diastole was regained later. This seemed to be related to the reduction in heart rate and moderate improvement in the prolonged isovolumic relaxation time (Fig. 2).

The pulmonary valve echocardiogram showed the deep " $a$ " dip in five cases, thought to be related to severe right heart failure. ${ }^{8}$ In previous echocardiographic studies on pulmonary embolism, only the increased dimension of the right ventricle and the paradoxical motion of the interventricular septum have been observed. ${ }^{1}$ In our cases, the increased dimension of the right ventricle was shown in all the 


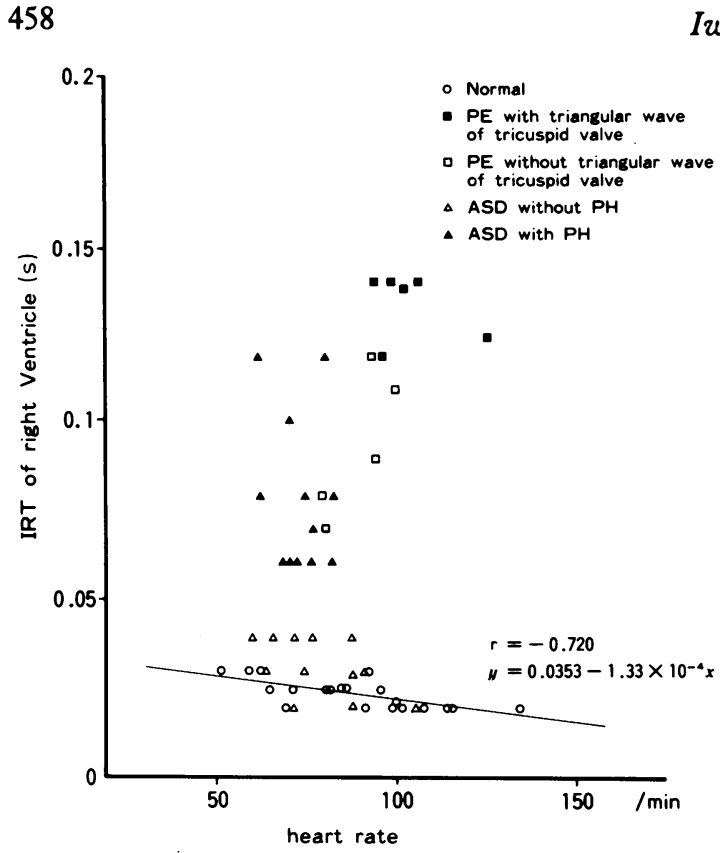

Fig. 2 The isovolumic relaxation time (IRT) plotted against heart rate for the four groups. PE, pulmonary embolism; $A S D$, atrial septal defect; $P H$, pulmonary hypertension. Regression line and correlation coefficient shown are for the control group.
Iwasaki, Tanimoto, Yamamoto, Makihata, Kawai, Yorifuji

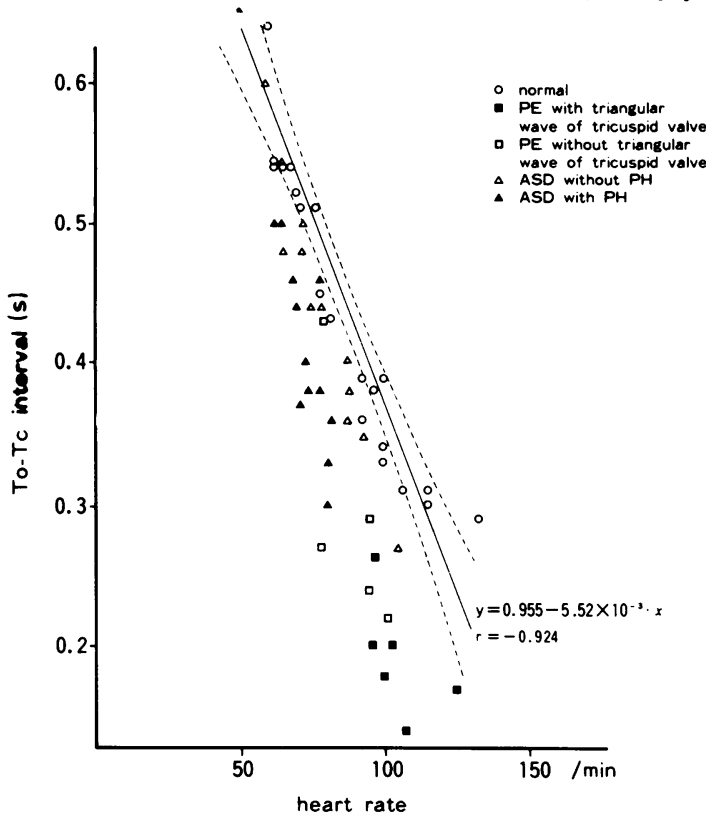

Fig. 3 The To-Tc interval plotted against heart rate for the four groups. Abbreviations in the following figures as in Fig. 2. Regression line and correlation coefficient shown are for the control group.

Table 2 Non-invasive measurement of cardiac interval data

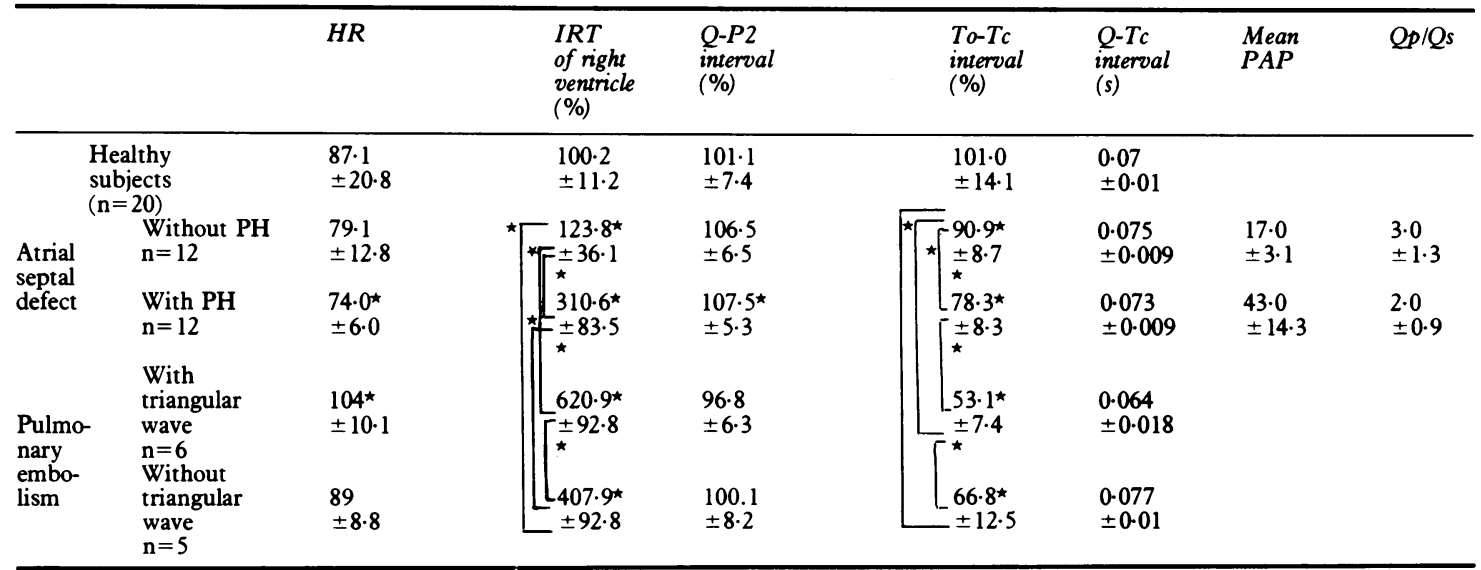

PAP, pulmonary arterial pressure; $\mathrm{PH}$, pulmonary hypertension; Qp/Qs, the ratio pulmonary and systemic blood flow. Other abbreviations as in text.

Asterisks $\left({ }^{\star}\right)$ indicate significant differences from the corresponding values of healthy subjects or between groups.

The regression equations used to calculate the cardiac intervals.

IRT, $0.0353-1.33 \times 10^{-4} . X(X=$ heart rate $) . Q-P 2=0.535-1.86 \times 10^{-3} . X$ To-Tc $=0.925-5.52 \times 10^{-3} . X$

The calculated value for each interval was expressed as $\frac{\text { measured value }}{\text { predicted values }} \times 100 .(\%)$. 


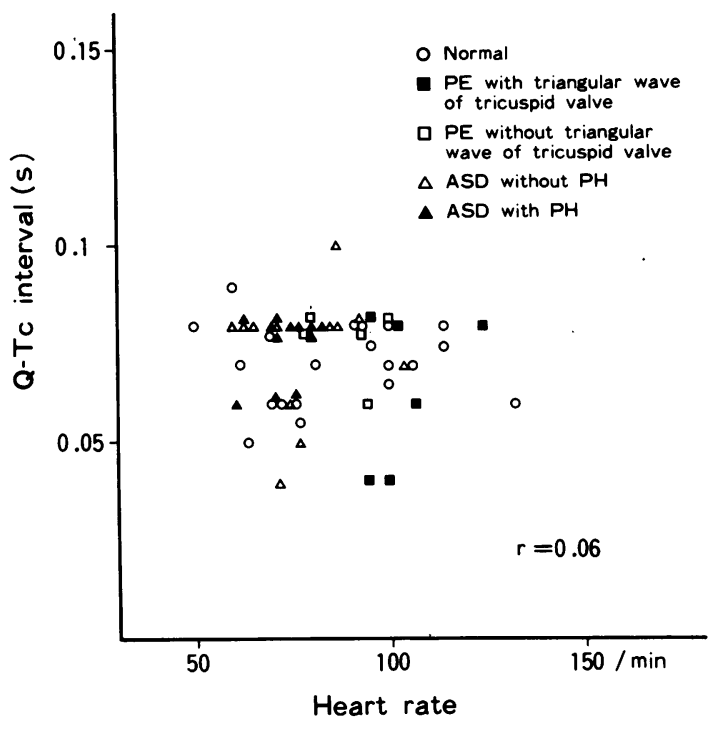

Fig. 4 The Q-Tc interval plotted against heart rate for the four groups. Correlation coefficient shown are for the control group.

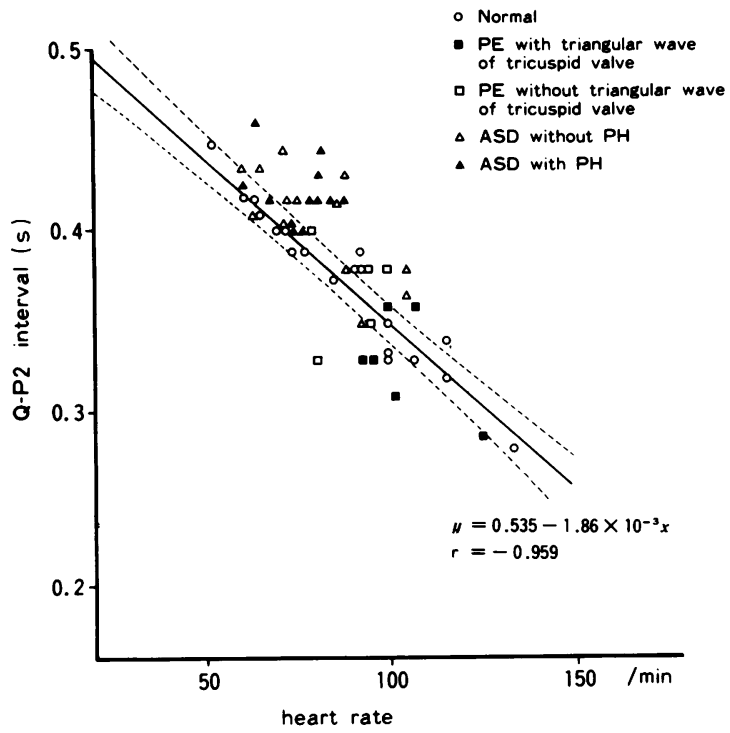

Fig. 5 The Q-P2 interval plotted against heart rate for the four groups. Regression line and correlation coefficient shown are for the control group.

Table 3 Measurement of right and left-sided cardiac interval data

\begin{tabular}{|c|c|c|c|c|c|c|c|c|c|}
\hline \multirow[t]{3}{*}{ Case No. } & \multirow{3}{*}{$\begin{array}{l}\text { Time after } \\
\text { onset }\end{array}$} & \multicolumn{4}{|c|}{ Tricuspid valve } & \multicolumn{4}{|c|}{ Mitral valve } \\
\hline & & \multirow{2}{*}{$\begin{array}{l}R R \\
\text { interval }\end{array}$} & \multirow{2}{*}{$\begin{array}{l}P 2-T c \\
\text { interoal }\end{array}$} & \multirow{2}{*}{$\underset{\text { interval }}{\text { To-Tc }}$} & \multirow{2}{*}{$\frac{T o-T c}{P 2-T c}$} & \multirow{2}{*}{$\begin{array}{l}R R \\
\text { interval }\end{array}$} & \multirow{2}{*}{$\begin{array}{l}A 2-M c \\
\text { interval }\end{array}$} & \multirow{2}{*}{$\begin{array}{l}\text { Mo-Mc } \\
\text { interoal }\end{array}$} & $M o-M c$ \\
\hline & & & & & & & & & $A 2-M c$ \\
\hline $\begin{array}{l}1 \\
2 \\
3 \\
4 \\
5\end{array}$ & $\begin{array}{l}10 \mathrm{~d} \\
24 \mathrm{~h} \\
12 \mathrm{~h} \\
20 \mathrm{~d} \\
12 \mathrm{~h}\end{array}$ & $\begin{array}{l}0.57 \\
0.59 \\
0.57 \\
0.55 \\
0.66\end{array}$ & $\begin{array}{l}0.28 \\
0.34 \\
0.30 \\
0.28 \\
0.34\end{array}$ & $\begin{array}{l}0.14 \\
0.20 \\
0.17 \\
0.17 \\
0.20\end{array}$ & $\begin{array}{l}0.50 \\
0.58 \\
0.57 \\
0.61 \\
0.58\end{array}$ & $\begin{array}{l}0.57 \\
0.57 \\
0.58 \\
0.57 \\
0.59\end{array}$ & $\begin{array}{l}0.34 \\
0.33 \\
0.35 \\
0.34 \\
0.35\end{array}$ & $\begin{array}{l}0.3 \\
0.3 \\
0.31 \\
0.3 \\
0.28\end{array}$ & $\begin{array}{l}0.88 \\
0.91 \\
0.89 \\
0.91 \\
0.80\end{array}$ \\
\hline $\begin{array}{l}\text { Mean } \\
\pm \\
\text { SD }\end{array}$ & & $\begin{array}{l}0.588 \\
\pm \\
0.038\end{array}$ & $\begin{array}{l}0.308 \\
\pm \\
0.027\end{array}$ & $\begin{array}{l}0.176 \\
\pm \\
0.022\end{array}$ & $\begin{array}{l}0.568 \\
\pm \\
0.037\end{array}$ & $\begin{array}{l}0.576 \\
\pm \\
0.008\end{array}$ & $\begin{array}{l}0.342 \\
\pm \\
0.007\end{array}$ & $\begin{array}{l}0.298^{\star} \\
\pm \\
0.01\end{array}$ & $\begin{array}{l}0.878 \\
\pm \\
0.04\end{array}$ \\
\hline
\end{tabular}

P2-Tc interval, the interval from closure of pulmonary valve to closure of tricuspid valve;

To-Tc interval, the interval from opening of tricuspid valve to closure of tricuspid valve;

A2-Mc interval, the interval from closure of aortic valve to closure of mitral valve;

Mo-Mc interval, the interval from opening of mitral valve to closure of mitral valve.

Asterisk $(\star)$ shows significant difference when compared with the corresponding values of right ventricle.

cases, whereas the paradoxical motion of the interventricular septum was not recognised.

In summary, we reported striking abnormalities of the tricuspid valve echocardiogram of pulmonary embolism, which are presumably in part related to the increased pulmonary artery pressure though there may well be other explanations. Further clinical and experimental studies are required to clarify the pathogenesis of the abnormalities of tricuspid valve motion in diastole and its significance in the evaluation of impaired right ventricular function in pulmonary embolism. 


\section{References}

1 Kasper W, Meinertz T, Kersting F, Löllgen H, Limbourg $\mathrm{P}$, Just $\mathrm{H}$. Echocardiography in assessing acute pulmonary hypertension due to pulmonary embolism. Am $\mathcal{F}$ Cardiol 1980; 45: 567-72.

2 Winer H, Kronzon I, Glassman E. Echocardiographic findings in severe paradoxial pulse due to pulmonary embolization. Am f Cardiol 1977; 40: 808-10.

3 Steckley R, Smith CW, Robertson RM. Acute right ventricular overload. An echocardiographic clue to pulmonary thromboembolism. Fohns Hopkins Med f 1978; 143: 122-5.

4 Feigenbaum H. Echocardiography. 2nd ed. Philadelphia: Lea \& Febiger, 1976: 87-107.

5 Burstin, L. Determination of pressure in the pulmonary artery by external graphic recordings. Br Heart $\mathcal{F} 1967$; 29: $396-404$.
6 Ito M, Fujino T, Kurata E, et al. Isometric contraction and relaxation times of right and left ventricles in normal subjects and in patients with right ventricular overloading measured with bidirectional echocardiography. $f p n$ Heart f 1978; 19: 193-203.

7 Weiss JL, Frederiksen JW, Weisfeldt ML. Hemodynamic determinants of the time-course of fall in canine left ventricular pressure. $\mathcal{F}$ Clin Invest 1976; 58: $751-60$.

8 Nanda NC, Gramiak R, Robinson TI, Shah PM. Echocardiographic evaluation of pulmonary hypertension. Circulation 1974; 50: 575-81.

Requests for reprints to Dr Tadaaki Iwasaki, The 1st Department of Internal Medicine, Hyogo College of Medicine, 1-1 Mukogawa-cho, Nishinomiya-shi, Hyogo 663, Japan. 